\title{
DESIGNING CREATIVE COLLABORATIVE LEARNING (CCL) FOR ECONOMICS: USING PROFESSIONALS AND VIDEO CLIPS IN MBA CLASSROOM
}

\author{
Frank Lorne \\ Professor of Management \\ Pavla Hlozkova \\ New York Institute of Technology, Canada
}

\begin{abstract}
Global economy is now characterized by frontier of models and theories that are often shaped by decision makers in global and national institutions. Creative collaborative learning (CCL) is attempted for this first time in a classroom environment for studying macroeconomics and world trade. CCL is suitable for student-centered learning MBA students who must put themselves through realistic situations, asking right questions, and making decisions. Traditional top-down methodology of emphasizing model building and mathematical proofs in studying macroeconomics are not suitable at the MBA level. The proposed CCL model in this study entails the joint efforts of three groups of players - the professionals, the students, and the instructor. Constructive knowledge is acquired not by drill and memorization of definitions, but by learning from the contexts in which terminologies are pragmatically applied, utilizing critical thinking. Professionals are invited to speak on industry topic, while specific video clips were searched and reviewed in C-span video library. The search and review exercise were analyzed by evaluating their effectiveness in motivating interests, learning of abstract terminologies, professional manner and articulation method, and recognizing the role of important institutions through the speaking professionals. CCL demands evaluations for "in-themoment" expressions and quotations that can "elevate thinking" in a studentcentered learning environment. Our paper illustrates how designs of CCL can be implemented in different topics on macroeconomics and world trade.
\end{abstract}

Keywords: Creative Collaborative Learning, Economics Methodology, Student-centered Learning 


\section{Introduction}

Economic concepts are often abstract and difficult to understand. They are particularly so for macroeconomics and global world trade issues. Learning difficult concepts can sometimes rely on bringing back the memory of an instructor(s) articulating the difficult concepts. The most used teaching approach in economics involves an instructor and a class of students, with information and knowledge being transmitted from top down. Students study definitions and formulas by memorization, but many of them don't really understand the true meaning, nor are they able to explain the concept or apply them in a real world conversational situation. Methods of articulation can take on an important learning role in this respect. When a student remembers something that an instructor taught in a class, it is usually an example or a proposition that the instructor had made that lingers in the mind of the student. The student identifies that proposition with the face of the teacher, perhaps also his expression and the manner of articulation at the moment of a lecture.

This paper suggests a Creative Collaborative Learning (CCL) approach for studying complex and evolving concepts by listening how these concepts are articulated by professionals, either through invited professional speakers into the classroom, or in an experiential and/or virtual setting through video clips of live conferences. There are knowledge areas where this type of approach may be particularly suitable. CCL has been advocated in many areas of learning (Gokhale, 1995;Thousand, Villa,Nevin, 2002;Peppler and Solomou, 2011; Jarry-Benn, 2013) . In the area of macroeconomics and world trade, global conditions have been changing rapidly since the financial crisis of 2008, partly driven by theories and global geo-politics, and partly driven by changes in cooperation and conflicts between countries. For world trade and globalization, our world has been complicated further by the internet economy breaking through country border lines. When the theories and models used in a subject are going through an evolutionary process of changes, the use of CCL is particularly relevant.

Macroeconomics for an MBA program became increasingly difficult to teach after 2008, instructor can no longer rely on old models, and new methods of studying the subject must be explored. CCL brings new dimension to students studying macroeconomics and world trade in that they can experience how professionals in the real world in conferences and in actual project implementation can shape evolving ideas. Collaborative learning is not unique in this respect. More and more disciplines have turned to the use of this methodology for a more applied focus for the discipline. For example, in entrepreneurial studies, there are frontier development using 
focused group studies to creatively what practitioners found important and interesting about their studies (Frank and Lundstrom, 2013).

This paper designs and studies the speaking of policy/opinion makers of macroeconomic and world trade by using a methodology of creative collaborative learning. Section 2 describes and compares the current predominate learning method and the Creative Collaborative Learning (CCL) method. We'll give several examples of speaking event in macroeconomic and world trade can be studied and analyzed using this approach. Section 3 explains how this methodology has been experimented in an MBA class. A survey to a sample of students was conducted, and some key results will be reported. Section 4 provides some concluding remarks.

\section{Section 2: Creative Collaborative Learning with an Example}

Before we bring up an example to illustrate the significance of CCL in learning in a changing environment, let us first compare the difference between traditional teaching and CCL. Traditional teaching approach includes the interaction between an instructor and a student where the instructor controls the whole learning process and makes decisions for the students. Information and knowledge are passed down from top to bottom. This learning method requires repetitive reinforcement, and students must acquire their knowledge through drill and practice. This type of learning mode may be best suited for sharpening skillset and knowledge that are unaltered, stable, and the utilization of the skill in the market place is competitive with speed of accomplishing a task being the most important criteria.

Student-centered learning method switches the information knowledge acquisition mode from top down to bottom up. Students' role is not passive, but are expected to acquire information and knowledge with their own initiatives, actively participating in a class environment, with the instructor playing a guidance role (Hannafin, Hall, Land \& Hill,1994;Connor, 2006). Students are engaged and personally responsible. This method supports selfreliance of students, conducive to critical and creative thinking, and promotes collaborative team work with students and instructor.

CCL differs from traditional learning method, involving three participants rather than two - Professional, Student and Instructor. Students (coached by an instructor) learn from professionals. An embedment of the concept of a practicum with a student-centered learning method, the methodology may be suitable for disciplines where theories and models evolved from decision makings of the professionals (rather than a well-set stock of knowledge preserved and handed down unaltered generations after generations, e.g. training to be a physician. The significance of a CCL model lies upon a self-driven acquisition of knowledge experience where a 
student's knowledge scope, theoretical, practical, and experiential, is expected to be formulated according to the career preference needs of the students, rather than predefined by the instructors or the professionals.

Preliminary thinking may suggest that CCL is best conducted in a live situation by engaging a professional articulating his expertise on a subject matter of relevance to a course. In a real world classroom setting, this can be impractical and at best very expensive. Our initial approach is to bring in C-span live conference into the classroom as a more practical substitute. Students try to understand problems through watching clips from the C-Span library where professionals discuss important macroeconomic and political issues were archived. A dialectic approach in studying and interpreting macroeconomic environments can then be brought into classrooms. This approach arguably is better than having an instructor directly instruct or a professional brought into a classroom to speak about a subject casually. First of all, speakers in a public forum have good incentives to do a good job in speaking performance, much more demanding than lecturing in a classroom. Secondly, C-span library prescreens sessions of substantive values and interesting to view, thus much more reliable than inviting a professional into a classroom where instructors have no control over the professional's performance. Thirdly, the ability to rewind and replay a clip can allow multiple viewings, catching up concepts easily missed in a real live conference setting. In addition, students also develop other skills for learning technical terminologies, as well as a way of presenting, learning of professional speaking mannerisms and how they handle questions and answers. That being said, there are offsetting values of having face-to-face interactions with professionals also. This will be elaborated further in the next section.

With invited professionals or with video clips, it is emphatically noted that CCL cannot be conducted without instructor's intervention. Professionals often concentrate only on a particular goal specific agenda in a conference delivery setting. Instructor's role in putting the agenda into perspective is exceedingly important. Instructor's intervention usually includes defining learning objectives, tracking collaborative efforts of students through some sort of monitoring, utilizing internet learning platforms such as Blackboard discussion, and requiring student presentations by offering critical comments, quizzes and exams, etc. An unconstrained CCL set up without instructor intervention is a sure recipe for failures, as students lack the background knowledge as well as a road map to probe the unknowns.

We used a C-Span recorded public speaking forum of Christine Lagarde of IMF and Janet Yellen of US Federal Reserve recorded on May 6, 2015 as an example for illustration. The topic of the forum was on lessons to 
be learned from the 2008 financial crisis. Janet Yellen talked about how a well-functioning financial system should promote job creation, innovation, inducing real economic growth. Financial system should channel savings to productive investment, promoting business creation and job formation. It also should help households save for retirement, purchase homes and cars, and weather unexpected misfortunes. However, the financial crisis of 2008 uncovered problems of excessive leverage, resulting in and fueling bubbles in the housing market. The reliance on short-term funding by many institutions left the system vulnerable to runs. There were excessive risktakings that ultimately had resulted in systemic risks to the system. To those problems, the Federal Reserve in US as well as other regulators have reestablished laws and regulations, e.g. capital requirements, liquidity coverage, etc., and the running of stress tests to monitor the health of financial institutions.

Yellen's prepared speech can mostly be found from various other publications, and it is useful to hear that directly from the mouth of the authority. However, the overall tone of the speech is for managing risks in the US financial system via regulations. This approach of course should not be ignored or denied by any prudent central bankers of the world. Indeed, in the subsequent speech given by IMF's Christine Lagarde, these problems and solutions were acknowledged. Lagarde's delivery was very different on style however, approaching the subject with a curious quotation of Voltaire: "If you see a banker jump out of the window, follow him because there is certainly money to be made..."

Here, an apparent elusiveness popped up. It generated curiosities in the mind of the audience beyond the usual expectation that financial crisis normally arises just from excessive risk taking. Lagarde's remark provoked laughter from the audience, but did lead to the hinting of a more serious side of the main message she was after. At one instance, she seemed to suggest that the window could have been the subprime market loans. If so, that remark would be to reinforce Janet Yellen's position of excessive risk taking of the financial system. Yet, at another instance of the speech, Lagarde seemed to be referring the window as the window separating the bank and the nonbank sectors of the financial system.

We note that exactly what she had in mind was not as important as the remarks' potential to generate inquiries and questions. In an MBA classroom environment, debates of a policy position as well as difference in interpretation can contribute to ultimate deep learning. If Lagarde's remark was perceived differently by different people, including herself, a focus discussion of the remark can possibly bring out many additional features of the functioning of the financial system, reflecting philosophical difference between the FED in US and the IMF, an international organization. 
Lagarde's remark on Voltaire is an excellent vehicle to provide this type of a learning experience. A student would need to review the segment several times in order to spot hints on what she really wanted to say. In many graduate schools, a study of someone's writing went through the same process. In that sense, the use of video clips is not unique to the contribution of critical thinking. Yet, for MBA class activities, a discussion of current issues spoken by an "authority-in-charge" is much more effective than studying the writing of some dead economists or professors in other universities who do not reward directly the students for studying their writings. In addition, being able to understand a live person in charge of important decisions could be more rewarding to MBA students than the knowing of the "truth" of knowledge, if there is such a thing in macroeconomics.

Lagarde's remark can also be contrasted with Janet Yellen's emphasis of laws and regulations as the method of dealing with excessive risks. Indeed, Lagarde took a different position at the end of the speech; "But regulation alone cannot solve the problem. Whether something is right or wrong cannot be simply reduced to whether or not it is permissible under law. We need a greater focus on promoting individual integrity.” She went on to articulate why financial inclusion (minority needs, etc.) could be equally important.

The contrast was revealed more sharply in her concluding statement: "One final point: I hear, and I have heard many times over [perhaps referring to Yellen's position], that it would be so much better if bankers were boring again. You know what, I fundamentally disagree with that, because it takes the view that for bankers to finance the real economy, it is boring...If the definition of boredom is working for the real economy, and the definition of excitement is just making a lot of money, I think we have to change a few things around here."

Upon reflection, Voltaire's quote could be interpreted as Lagarde's urging of what bankers should be doing, or what is the proper window for the bankers to jump out to. If bankers are to be broadly interpreted as financiers, jumping out from the window could very well be referred to money being put into the main street where real economic activities matter (rather than just financial dealings- - "making a lot of money"). In that sense, Lagarde's speech seemed more coming from an idealized perception of what a financial system should be, drawing distinction between financial deepening vs. financial inclusion, urging aspiration of financial inclusion for women and low-income individuals, etc. .Traditionally, these aspirations are subject matters not usually considered by IMF, as the original intention of IMF was to assist balance of payment problems of member countries. The implication of this elevation of thinking, if inferred correctly, can be subtle, 
profound and controversial: A boring banker stays in a room, with money forever staying within the financial system, although in different forms in the system, e.g from banks to nonbanks. By contrast, an exciting banker jumps out of the window to the main street. This is a point that had not been featured well in traditional economics textbooks as well as the emphasis used in most classroom lectures. Unfortunately, along this direction of inquiry, the ensuing dialogue between Yellen and Lagarde was silent. A replaying of a video clip can make the silence more pronounced. The dialogue exchange dynamics itself can be insightful.

It is also important to point out a postscript to this learning exercise: In June the same year, IMF Lagarde further issued a statement urging US Federal Reserve to delay the raising of interest rate in September as a majority of financial experts in US believed US should act. At the time the statement was issued, it was largely scoffed off by the financial commentators in US in the media. As it turned out, the world events evolved from June to September in such a way that US Federal Reserve indeed did not raise interest rate in September. To be sure, this does not prove or disprove anything concerning an evolving relationship between USA and the rest of the world; but it is a policy observation worthy of discussion in a classroom environment for further anticipating actions for the future.

\section{Section 3: Designing MBA classroom experiments}

We progressed to formulate an experiment first for a macroeconomic MBA class with the following four learning objectives in video clip evaluation. Subsequent refinement of was also implemented in other courses. Those implemented in the macroeconomic course were:

1. An understanding of the recent issues in an economy of a country as articulated or projected by the speaker.

2. A recognition that there are pros and cons for every macro policy decision made.

3. An appreciation of in-the-moment expression of thoughts by policy makers of macroeconomics.

4. An elevation of thinking by reading into the expression of how policy makers articulate concepts or the points of contention.

Step 1 - Students in a class were to form country focus teams-e.g. USA, Canada, India, China, Brazil. To prepare for a study of issues of relevance in a country, each team was asked to research on the socioeconomic characteristics of the country, e.g. GDP, population, GDP/capita, growth rate, political system, inflation rate, unemployment rate, strength of its domestic currency.

Step 2 - Students were then asked to focus on a search on the C-span video library for particular video recordings related to the issue in the 
country which they were assigned. This should be an individual effort where each member of the team will work independently to look for a clip from the C-span video library.

Step 3 - Students were encouraged to communicate to other team members about difficulties and specific terminology used in the clip. They were asked to write down excerpts from a clip each individually selected in the form of a table aligned for the 4 objectives above. They were also asked to write down (a method of "brain writing") the reasons why an excerpt was chosen for each objective.

Step 4 - Students were engaged in a group discussion for coming up with a team template for the country's study. The team could use ONE clip for all four objectives, or one clip for each objective. They were asked to rank an excerpt on the basis of the extent by which a clip matches an objective ( scale 1-5, 5 the highest score). A team member might not has fully understood an objective and picked an excerpt that did not meet the objective. If so, the numerical ranking of that excerpt should be low. The team has to collaboratively decide on what excerpt best served an objective.

From the team template, we note some successes and failures: Instructor Intervention via Learning Objectives $1 \& 2$ generally was quite effective. Students were able to distill facts about recent economy from the speech of a speaker. Even in the case where a clip is not recent, they were able to project propositions said in the past for the present state of the economy. The evaluations of the pros and cons of policy decisions were a bit of a mix. Some have difficulties in distinguishing between policy decisions and economic observations. The former is a subjective decision, the latter is an outcome. Some students do not have the analytical maturity to distinguish between the two. Relative to objectives $3 \& 4$, excerpts were more easily detected and communicated in writing. Generally speaking, objectives 1 \&2 were more suitable for "beginner" students of macroeconomics.

We did not achieve the same degree of effectiveness for objectives 3\& 4. Many students did not understand what expressions would belong to the category of "in-the-moment". Perhaps it is necessary that an overall main message of the speaker must first be understood thoroughly before a subliminal message is to be detected. Therefore, students need to understand the whole context of macroeconomic agenda pursued by a speaker in order to filter out some inner thoughts of the speaker. Yet, it is the expression of those inner "in-the-moment" thoughts that open up rooms for creative collaboration. A participant to a creative collaborative process would seize the moment and pursue inquiries in a direction unintended in the original preparation of an agenda driven speech. The same is true for the objective of "elevation of thinking". A listener must have some priors before listening to a message in order for the speech to elevate the thinking of the priors. If a 
listener does not have priors, there cannot be an elevation of thinking because there is nothing to elevate from. Because of that, perhaps objective 4 is for more suitable for advanced macroeconomics students.

A survey was subsequently conducted for a sample of students asking questions on the following 4 dimensions of C-span video clip appreciations:

I. Effectiveness in Motivating Interests

II. Learning of Abstract terminologies

III. Learning of Professional manner and articulation method

IV. Recognition of the role of Institutions

The questions associated with each dimension are reported in the Appendix. Some key findings are noted below:

For I: Out of 12 respondents, 11 said their interests on macroeconomic issues have increased. The student responded negatively said "I took this course for requirement thus indifferent about interests". For the 11 responding positively, they were able to identify specify reasons on why the video viewing had benefited them and their interests on macroeconomics issues have increased.

For II: All respondents remembered at least one abstract concept learned from the course and one abstract concept learned from the video clip. All except one remembered the face of the professional with the abstract concept. All did additional search of the abstract terminologies identified via the clips in the library or on the internet.

For III: $\quad$ All acknowledged professionals can be role models for them to learn. Relative to learning from instructor versus learning from professionals, 4 ranked the two mentors equally effective, while 8 chose professionals being more effective. For improving English, all except one learned better with the professionals. This could be due to the fact that English is not the native language of the instructor in this experiment.

For IV: Only 3 out of 12 respondents recognized the role of institution in the clips they chose to review. 8 referred to the Yellen-Largarde clip, which was the example used by the instructor, not the clip they were supposed to review. One respondent's answer was deleted because of its misunderstanding of the question. Most respondents believed future ideas and models in macroeconomics will come from opinion leaders and policy makers, although 1 or 2 of them picked professors.

The most interesting achievement of this experiment was the survey result showing that students were able to remember a concept from their class, and identified that concept with the face delivering it. Theoretically, the attempt to associate difficult concepts with a face of delivery is the same as used in great movie scripts. Many people cannot remember a movie they have seen, but they may be able to remember a particular scene and a particular line delivered through the mouth of the actor. That, often, can 
have a bigger impact for someone whose goal is to acquire a perspective rather than the sharpening of a skill. Arguably, that should be the emphasis of learning macroeconomics today. CCL is a means to achieve that objective of shaping a student-centered method of acquiring knowledge on abstract concepts such as those in macroeconomics as well as in other courses dealing with abstract theorizing.

With that directional goal for improvement, we believe CCL can be further enhanced in a classroom environment by adopting the following:

1. The duration of a course must be longer, at least 15 weeks. Students need time to digest new material and concepts, not to mention research time for extension of concepts.

2. Some additional intervention and monitoring mechanism have to be developed so that every member of a team could keep track of the progress of the collaborative learning exercise. Developing an evaluation exercise at the end of each step will be a way to make sure that there's no free riders in team effort.

3. The timing of basic tools for thinking in coordination with the time table of the collaboration exercise will be a challenge. Not every member of a team is as motivated to learn macroeconomics issues and has the same background knowledge of macroeconomics.

4. A point reward system needs to be developed so that leadership in collaborative learning would not be seen as futile and irrelevant efforts on the part of a motivated student. The best way to learn is to learn how to teach others. This is a managerial mission in every organization. It is suitable for an activity in an MBA classroom to embrace that feature into their team work.

5. It is perhaps not feasible to make learning on macroeconomics to be totally based on collaborative creative learning. The mix of prior knowledge with emerging self-learning knowledge most likely cannot be uniformly determined for all classes. The optimal mix ratio will a function of prior knowledge, the cultural background as far as studying habits, and the motivation of students in the taking of the course.

Several of these design measures were subsequently adopted in a course of 15 weeks emphasizing world trade. The CCL format used a combination of video clips and invited professionals as guest speakers in a three-hour duration. Students were asked to read assigned articles of relevance to the topic of the speaker of the day. The first hour of the class was for the professional speaker to speak to the class. In the second hour, the class was broken into teams to work on specific assignments (questions) provided by the instructor. A metric of how team works should be best conducted was distributed to everyone in the class. Instructor made periodical visits to each team as an observer to monitor collaborative 
intensities, the extent of ideas exchange, and whether substantive creativity elements were involved. Students were asked to return to class room to make a presentation of the findings of their team, and specifically answered the questions posted by the instructor.

In a class of 19 students ( 4 teams), CCL were found to be challenging to students but of good learning values. Creative student-initiated propositions were detected much more often than the CCL conducted in a short 6 week course on Macroeconomics, often showing instances of "elevation of thinking", distinctly providing propositions beyond what the professional invited speakers were saying.

However, students commonly believed that the one hour team work time is too short. The design of this short delivery cycle was deliberate, as working managers in the real world often have to work under time constraints to produce reports. On the positive side, students attention span were highly improved using this method, as every student will be working in a small group environment assuming certain role, as opposed to a conventional classroom of instructor lecturing top down, where individual student can be completely withdrawn and not actively participating without the instructor knowing about it. Some students commented, "the class goes so fast that you look at your watch to meet short-term deadline, not to check when the class will end.”

Another challenge team work has to confront was how creative ideas were received and debated with teammates. Individual team member may not have the communication skill to fully express his/her thoughts to the team, even in a small group environment. Language barrier of international student body can further complicate the practicality of this endeavor. Our instructional design adopted several features of CCL to cope with this.

1. Instructor collected notes each team provided. An individual when overwhelmed by language difficulties can still jolt down key words he/she wishes to express, and provide further information to instructor when time permits after a class.

2. An "articulator" of a team is assigned the role of summarizing and articulating the results of the team to the class. Member of a team takes turn to be the articulator, and each member should do it at least once in the course. The articulator has the full authority within the ideas discussed in the team on which idea to articulate and present to the class. For example, a particular individual may be handicapped in whatever way in a team environment, but when it is his/her turn to be the articulator, the person has the complete authority to choose the ideas discussed within the team that the person wishes to articulate. Furthermore, given a time constraint of 10 minutes in oral 
presentation, language handicaps would not be overly taxing on class time when it comes to presentation for the whole class.

3. Feedbacks and interventions from the instructor and/or invited professionals can determine the success of a particular CCL exercise. The format as it was set up allowed intervention only for the last hour of a class. Drawing conclusions in the form of postscripts sent by emails after a class exercise is still another way to provide feedbacks. It may be important to emphasize that a CCL exercise should not aim at actually creating new ideas, and be evaluated as such. To do so will be an impossible goal set for the students as well as the instructor. Rather, the purpose should be set for an attempt to engage in creative thinking. The analogy of a physician attempt to make a patient healthy can be used. It is not important for the physician to define what healthiness means in order to engage a patient into a recovery exercise. It is more important to monitor whether the blood pressure of a patient has improved or got worse after each engagement exercise. For the monitoring of CCL, the subjective opinion of the instructor could be further challenged by students in evaluating a holistic approach for learning. There is yet to be a completely objective measure of success that needs to be further defined.

4. In addition to providing a detailed metric for evaluating team work performance (ranking from minimal standard to outstanding performace), we also designed a questionnaire for a team to evaluate their team members' contribution to the team. To be sure, the questionnaire was structured in a way that negative comments directed toward a particular member will not affect the grade of the member who was criticized, but will reward an individual in a team who receive majority positive comments from team members. This can alleviate the pressure and the time constraint imposed when the team is working together, but at the same time, recognizing individual contribution on creative thoughts as well as the extent of helping other team members.

\section{Conclusion}

Economic environments in the world have been changing, due to globalization and technological advances. Creative Collaborative learning (CCL) is suitable for MBA students in understanding these changing environments because it provides an experiential/virtual reality learning encounters with important policy makers from recognized institutions. As revealed in the key findings, students must put themselves through realistic situations and learn to ask right questions, be able to make decisions and be 
able to communicate macroeconomic and world trade issues, including advances on internet commerce, in daily or public conversations.

\section{References:}

Butterworth, Margaret. "The Concept of the Virtual School Library.” Paper presented at the Annual Conference of the International Association of School Librarianship (21st, Belfast, Northern Ireland, July 20-24, 1992).

Connor, Peter."Student-Centered Instruction: A Brief Description" http://teaching.colostate.edu/tips/tip.cfm?tipid=60. 2006.

Davis, Nicholas."How can Europe become more innovative?” https://agenda.weforum.org/2015/08/how-can-europe-become-moreinnovative. 2015

Frank, H. and H. Landström. That's interesting! An empirical study on what makes entrepreneurship research interesting, paper presented at the XXVII RENT Conference, Vilnius, Lithuania, 21-22 November, 2013.

Gokhale, Anuradha A. "Collaborative Learning Enhances Critical Thinking", Journal of Technology Education, Vo.7, Iss:1, http://scholar.lib.vt.edu/ejournals/JTE/v7n1/gokhale.jtev7n1.html?ref=Sawos.Org. 1995.

Hannafin, M.J., Hall, C., Land, S.M. \& Hill, J.R.. ”Learning in open-ended environments: Assumptions, methods, and implications." Educational Technology 34(8): 48-55, 1994.

Hannafin, M.J., \& Land, S.M.. "The foundations and assumptions of technology-enhanced student centered learning environments.” Instructional Science, 25, 167-202, 1997.

Jaray-Benn, Csilla.”Collaborative Creative Learning in Professional Training” IATEFL Hungary Conference, Budapest, 4 - 6 October 2013, http://www.academia.edu/8086938/Collaborative_Creative_Learning Keep, Ros. On-line: electronic mail in the curriculum. Warwick: National Council for Educational Technology, 1991.

Lorne, Frank and Pavla Hlozkova. "Creative Collaborative Learning for Macroeconomics:C-Span Video Clips in MBA Classroom.” 2nd Global Conference on Contemporary Issues in Education, GLOBE-EDU 2015, 2728 August 2015, Chicago, USA

Peppler, Kylie A. , Maria Solomou. "Building creativity: collaborative learning and creativity in social media environments", On the Horizon, Vol. 19 Iss: 1, pp.13 - 23, 2011.

Matthews, Chris. "IMF's Christine Lagarde to Janet Yellen: Please don't raise interest rates!” Fortune, June 4, 2015.

http://fortune.com/2015/06/04/imf-interest-rates/

Thousand, Jacqueline S., Villa, Richard A.,,Nevin, Ann I., Editors. Creativity and Collaborative Learning: The Practical Guide to Empowering Students, 
Teachers, and Families, 2nd Edition. Paul H. Brookes Publishing Co:Baltimore, USA, 2002.

C-Span Library Clip: http://www.c-span.org/video/?325849-1/christinelagarde-janet-yellen-financial-crisis. May, 2015. 